\title{
Cytokine expression in synovial membranes of patients with rheumatoid arthritis and osteoarthritis
}

\author{
M Nabil Farahat, Ghada Yanni, Robin Poston, Gabriel S Panayi
}

\begin{abstract}
Objectives-To compare, by immunohistochemistry, the cellular and cytokine profile in rheumatoid arthritis (RA) and osteoarthritis (OA) synovial membranes (SMs). Synovium was obtained at knee arthroplasty from 10 patients with $R A$ and 10 with $O A$.

Methods-Synovial membranes were stained with a panel of monoclonal antibodies (MAb) to assess cytokine

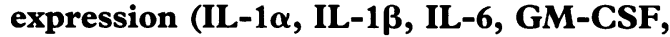
TNF- $\alpha$ and EGF) and the intensity of the mononuclear cellular infiltrate (MNC). Results-Significantly greater percentages of IL-1 $\alpha$, IL-1 $\beta$, IL-6, TNF- $\alpha$, GMCSF and EGF cells were detected in all areas of the rheumatoid SMs when compared with osteoarthritic SMs. Five RA but only one OA SM demonstrated focal lymphoid aggregates. Lining layer thickening was noted in RA SMs only. The intensity of the MNC and number of blood vessels were greater in the RA group. Conclusion-The results suggest that the differences in cytokine production by $R A$ and OA SMs are quantitative but that the greater thickness of the synovial lining layer and higher vascularity may be specific to RA.
\end{abstract}

(Ann Rheum Dis 1993; 52: 870-875)

The characteristics of chronic synovial inflammation are well described in rheumatoid arthritis (RA). They include vascular proliferation, changes in the morphology of endothelial cells, the accumulation of $\mathrm{CD} 4$ positive $T$ lymphocytes of the CD45RO positive memory subset and synovial lining layer thickening due to an increase in the type A and type B cells. ${ }^{1}$ In RA, it is believed that synovial inflammation is the primary event which leads to cartilage degradation and that the most important mediators in this process may be cytokines.

Cytokines have been detected in the synovial fluids and tissues of patients with RA. Recent studies have shown that in the RA synovium $T$ cell cytokines such as interleukin-2 (IL-2), interleukin-3 (IL-3), interleukin-4 (IL-4), gamma interferon $(\mathrm{IFN}-\gamma)$ and tumour necrosis factor beta (TNF- $\beta$ ) are present in low concentrations or absent, whereas macrophage products such as interleukin-1 (IL-1), interleukin-6 (IL-6), interleukin-8 (IL-8), tumour necrosis factor alpha (TNF- $\alpha)$ and granulocyte macrophage stimulating factor (GM-CSF) are abundant; these observations have led to the macrophage hypothesis as distinct from the T cell hypothesis in RA. ${ }^{2}$

The pathogenic basis of OA, by contrast, is less clear cut. Variable degrees of inflammation are common in OA, both clinically and pathologically. Inflammation at the onset of $\mathrm{OA}$ in the SM may be secondary to cartilage destruction or may be the primary cause. The histological features, which include the presence of $\mathrm{MNCs}$, may be indistinguishable from RA. ${ }^{3}{ }^{4}$ Although it has been proposed that $\mathrm{OA}$ is a synovial disease, experimental models and clinical observations in humans suggest that mechanical factors may be important. There is synovitis in the mechanical models of $\mathrm{OA}$; hence cytokine production within the synovium cannot be excluded. ${ }^{5}$

The aim of this study was to compare by immunohistology the SM cellular and cytokine profiles of patients with RA and OA to see if these two conditions could be distinguished by these means.

\section{Patients and methods}

PATIENTS

Synovium was obtained at knee arthroplasty from 10 patients with definite or classical RA, ${ }^{6}$ two men and eight women, mean age 53 years range $34-68$, and 10 patients with $\mathrm{OA}$, three men and seven women, mean age 61 years range $50-72$.

TISSUE PREPARATION AND STAINING

Synovial specimens were snap frozen within 30 minutes, after orientation in optimal temperature cutting compound (OCT), in isopentane cooled in liquid nitrogen. Samples were stored at $-70^{\circ} \mathrm{C}$ until sectioned for immunohistological staining for which $5 \mu \mathrm{m}$ sections were cut with a cryostat (Leitz) at $-20^{\circ} \mathrm{C}$. Sequential sections were mounted on APES coated slides and dried overnight at room temperature. Sections were fixed in acetone for 20 minutes, wrapped in tin foil and stored at $-70^{\circ} \mathrm{C}$ until further use. The $\mathrm{mAb}$ used to determine cellular content were UCHT1, OKT4, OKT8 and EBM11 (antiCD3, anti-CD4, anti-CD8 and anti-CD68 respectively; Dako Laboratories, Copenhagen, Denmark), UCHM1 (anti-CD14, gift of Dr N 
Hogg, ICRF, London), 27E10 and RM3/1 (early monocyte and late macrophage markers respectively, gift of Professor C Sorg, Germany). Anti-factor VIII related antigen (Factor VIII) (Dako laboratories, Copenhagen, Denmark) was used to stain endothelial cells. The mAbs used to determine cytokine expression were anti-IL-1 $\alpha$ (gift of $\mathrm{Dr} R$ Thorpe, NIBSC, Potters Bar), anti-IL-1 $\beta$ (gif of Dr D Boraschi, Italy), anti-IL-6 (gift of Dr T Hirano, Osaka, Japan), anti-TNF- $\alpha$ (gift of Dr M A Cousin, Roussel, Romainville, France), anti-GM-CSF (gift of Dr K Ruedi, Sandoz, Basel, Switzerland) and anti-EGF (gift of Dr S Shiozawa, Kobe, Japan).

Briefly, the primary mAbs, at appropriate dilutions (27E10 and $\mathrm{RM} 3 / 1$ at $1: 50$, antiCD3, anti-CD4, anti-CD8, anti-CD14 and all anti-cytokines at $1: 100$ and FVIII $1: 2000$ ) in phosphate buffer saline (PBS), were incubated on synovial tissue sections in a humidified chamber at room temperature for two hours for cytokine staining and for 45 minutes for cellular antigen staining, after an initial incubation for 10 minutes with a 1:20 dilution of normal rabbit serum. The excess $\mathrm{mAb}$ was removed by washing with PBS. After absorption with human liver powder diluted at 1:20 in normal human serum, the second antibody, biotinylated rabbit anti-mouse IgG (Dako laboratories, Copenhagen, Denmark) diluted in PBS at 1:300, was added and sections were incubated for 30 minutes. This was followed by washing with PBS and incubation for 45 minutes with avidin-biotin peroxidase complex (ABC Vecta Stain Kit, Vector Laboratories, Ontario, Canada). The sections were developed in a solution of diaminobenzidine tetrahydrochloride $(0.7 \mathrm{mg})$ $\mathrm{ml}$ ), and counterstained with haematoxylin. Finally, sections were dehydrated by transferring through alcohol and CNP30 and mounted in DPX.

Negative control staining was performed on all synovial specimens studied. This was identical except that incubation with the primary $\mathrm{mAb}$ was omitted, and no staining was noted in these sections. Tonsil tissue was used as a positive control. Other controls included MOPC21, a non-immune mouse IgG1 myeloma protein was used at equivalent protein concentration.

\section{CONFIRMATION OF CYTOKINE}

IMMUNOREACTIVITY

The specificity of the cytokine mAbs has been extensively studied and demonstrated by the providers of these proteins. TNF- $\alpha$ (personal communication from M A Cousin, Roussel) was obtained after fusion of immunised BALB/ c spleen cells with SP2/0-Ag14 myeloma cells. Partially purified murine immunoglobulins (sodium sulphate precipitated from ascitic fluid dissolved and dialysed in PBS) was used. This antibody did bind to r-Hu-TNF- $\alpha$ coated on ELISA plates and neutralised r-Hu-TNF$\alpha$ cytotoxic activity an L929 cells. The specificity of the other cytokine mAbs has been documented in published manuscripts; IL- $1 \alpha,{ }^{7}$
IL-1 $\beta,{ }^{8}$ GM-CSF, ${ }^{9}$ IL-6 ${ }^{10}$ and EGF. ${ }^{11}$ Furthermore, the specificity of the binding of these antibodies to synovial tissue was confirmed by: (1) staining with cytokine $\mathrm{mAb}$ which was concentration dependent; (2) using MOPC21, a non-immune mouse IgG1 myeloma protein without antibody activity at equivalent protein concentration, as an irrelevant antibody; (3) comparing the pattern and degree of staining by multiple clones for the same antibody on synovial tissue and tonsil which yielded the same pattern of staining; (4) applying mAbs on separated peripheral blood mononuclear cells (PBMCs) before and after PHA stimulation which resulted in increased expression of all cytokines examined in PHA stimulated PBMCs compared to nonstimulated PBMCs.

MICROSCOPIC EVALUATION

In each patient studied a minimum of four different synovial tissue samples were examined. Cytokine expression and the intensity of the cellular infiltrate were assessed in three areas of the SM: (1) lining layer; (2) perivascular aggregate, where there was a cellular infiltrate of at least five cells in depth surrounding a central vessel; (3) connective tissue, where mononuclear cells were randomly arranged throughout the area without the formation of discrete perivascular aggregates. Lymphoid aggregates were required to be clearly defined with a minimum of 10 cells in depth around a central vessel.

Microscopic evaluations were performed by one observer (NF) who was 'blinded' to the name of the patients. Furthermore, to rule out intra-observer variation, samples from five patients were read on three different occasions. No statistically significant differences were observed between the three readings. Samples were also assessed by another observer (GY); the results were in agreement with those of NF.

(A) Cytokine staining: Cytokine expression was assessed by estimating the intensity of staining and the number of positively staining cells in the three areas defined above. The intensity of staining was estimated by devising a visual analogue scale (VAS) from $0-15 \mathrm{~cm}$, where 0 indicated no staining at all and 15 maximal staining. All sections (minimum of four different synovial tissue samples per patient) were examined and results were expressed as a mean. For the number of positively staining cells, a total of 200 cells were examined in each of the areas, for each synovial

Table 1 Histological features of the synovial membrane in patients with rheumatoid arthritis $(R A)$ and osteoarthritis $(O A)$

\begin{tabular}{llll}
\hline & $\begin{array}{l}R A \\
(n=10)\end{array}$ & $\begin{array}{l}O A \\
(n=10)\end{array}$ & $p$ \\
\hline Focal aggregates & 5 & 1 & \\
Lining layer (Cell depth) & $7 \cdot 2(3 \cdot 0)$ & $3 \cdot 3(2 \cdot 0)$ & 0.01 \\
Vessel numbers & $9 \cdot 6(3 \cdot 1)$ & $6.5(2 \cdot 4)$ & 0.03 \\
\hline
\end{tabular}

Results expressed as mean (SD).

Vessel numbers per high power field $\times \mathbf{4 0}$.

NS = not significant 
Table 2 Mononuclear cellular infiltrate

\begin{tabular}{|c|c|c|c|c|c|c|c|c|c|}
\hline & \multirow{2}{*}{$\begin{array}{l}\text { Lining layer } \\
R A\end{array}$} & \multirow[b]{2}{*}{$O A$} & \multirow[b]{2}{*}{$p$} & \multirow{2}{*}{$\begin{array}{l}\text { Perivascular } \\
R A\end{array}$} & \multirow[b]{2}{*}{$O A$} & \multirow[b]{2}{*}{$p$} & \multirow{2}{*}{\multicolumn{2}{|c|}{$\begin{array}{l}\text { Connective tissue } \\
R A\end{array}$}} & \multirow[b]{2}{*}{$p$} \\
\hline & & & & & & & & & \\
\hline CD3+ & ND & ND & & $35 \cdot 6(19 \cdot 5)$ & $11(8 \cdot 5)$ & 0.002 & $25(22 \cdot 1)$ & $3 \cdot 2(3 \cdot 7)$ & 0.003 \\
\hline CD4+ & ND & ND & & $41 \cdot 3(22 \cdot 6)$ & $8 \cdot 5(7 \cdot 6)$ & 0.002 & $13 \cdot 5(19 \cdot 8)$ & $7 \cdot 6(8)$ & NS \\
\hline CD8+ & ND & ND & & $28(17 \cdot 1)$ & $9 \cdot 6(9 \cdot 6)$ & 0.005 & $9 \cdot 2(7 \cdot 1)$ & $5 \cdot 2(6 \cdot 8)$ & NS \\
\hline $27 \mathrm{E} 10+$ & $24 \cdot 1(19)$ & $16 \cdot 7(13 \cdot 4)$ & NS & $22 \cdot 4(18 \cdot 5)$ & $8 \cdot 4(6 \cdot 1)$ & 0.05 & $13(9)$ & $6 \cdot 5(6 \cdot 7)$ & NS \\
\hline CD14+ & $13 \cdot 2(7 \cdot 2)$ & $13 \cdot 1(8 \cdot 2)$ & NS & $27 \cdot 5(13 \cdot 8)$ & $10 \cdot 2(7)$ & 0.01 & $15.9(11.9)$ & $6.5(6.5)$ & 0.003 \\
\hline CD68+ & $66 \cdot 1(20 \cdot 5)$ & $43 \cdot 6(23 \cdot 3)$ & 0.01 & $60 \cdot 9(22 \cdot 8)$ & $11 \cdot 6(7 \cdot 6)$ & 0.002 & $35 \cdot 4(16 \cdot 6)$ & $13.5(10 \cdot 7)$ & 0.01 \\
\hline $\mathrm{RM} 3 / 1$ & $17(12 \cdot 2)$ & $14.4(7 \cdot 8)$ & NS & $14.5(15 \cdot 2)$ & $4 \cdot 7(5 \cdot 1)$ & 0.05 & $11 \cdot 4(11 \cdot 3)$ & $3 \cdot 7(4 \cdot 6)$ & NS \\
\hline
\end{tabular}

Results expressed as mean (SD) percentage of positively staining cells, ND = not detected, NS = not significant

tissue sample, and the number of positively staining cells was expressed as a percentage. Positivity was noted when complete staining of the cell was observed.

(B) Mononuclear cellular infiltrate: the number of cells staining positively for a particular cell marker was counted out of a total of 200 cells in each of the lining layer, perivascular and connective tissue areas, in a minimum of four different synovial tissue samples per patient, and the results expressed as a percentage.

(C) Synovial lining layer thickness: synovial lining layer thickness was estimated by assessing all visible lining layer in all synovial tissue samples at a magnification of $\times 400$. The thickness was quantified according to the cell depth. Three random readings per high power field (HPF) were recorded and the results expressed as a mean.

(D) Vessel number: vascular proliferation was estimated by counting the number of blood vessels staining with FVIII per HPF at
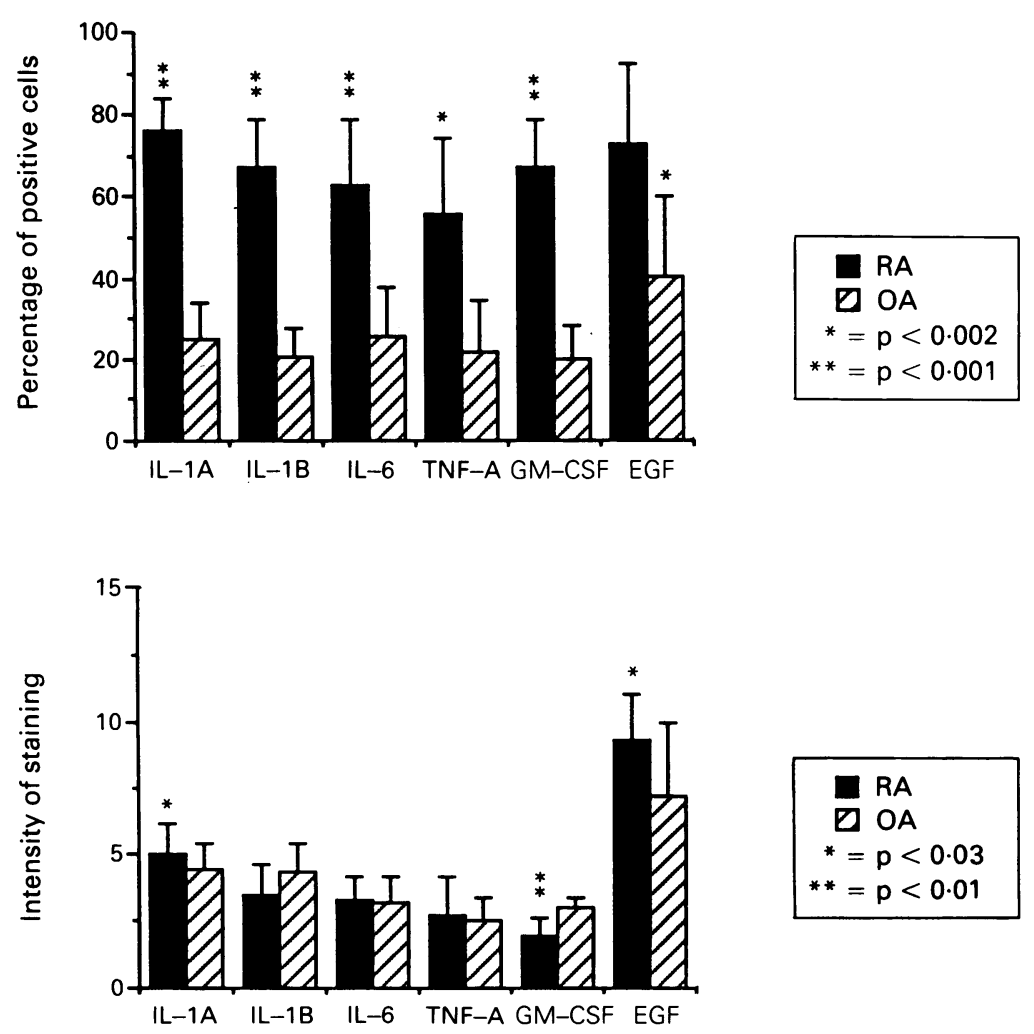

Figure 1 Measurement of the cytokines interleukin-1 alpha (IL-1A), interleukin-1 beta (Il-1B), tumour necrosis factor alpha $(T N F-A)$, interleukin-6 (IL-6), epidermal growth factor (EGF) and granulocyte macrophage-colony stimulating factor (GM-CSF) in the lining layer of the synovial membranes of patients with rheumatoid arthritis and osteoarthritis. Upper panel: percentage of positively staining cells; lower panel: intensity of staining. a magnification of $\times 400$ and expressing the results as a mean.

STATISTICS

Results are expressed as mean (SD). Histological scores in the different patient groups were compared using the Wilcoxon signed rank test.

\section{Results}

HISTOLOGICAL FEATURES

Five RA and only one OA SM demonstrated distinct lymphoid aggregation. Significantly greater lining layer thickening and vascular proliferation were also observed in RA but not OA SM (table 1).

CELLULAR COMPOSITION

Examination of the cellular infiltrate revealed differences between OA and RA in all areas examined (table 2). In the lining layer, 27E10+, CD14+ and RM3/1+ monocyte/ macrophages were similar in both patient groups. CD68+ cells, expressed on mature macrophages, were more numerous in RA compared with OA SM [mean (SD) $66 \cdot 1(20 \cdot 5) \quad v \quad 43 \cdot 6(23 \cdot 3) \%$ respectively; $\mathrm{p}<0.01]$. In the perivascular areas, there were significantly greater numbers of positively staining cells of all the cellular antigens examined in RA SM compared with OA and especially of $T$ cells and different forms of macrophages. In the connective tissue areas, greater percentages of positively staining $\mathrm{CD} 3$, CD14 and CD68 cells were observed in RA SM.

CYTOKINE EXPRESSION

Cytokine expression was estimated by assessing the intensity of staining and by counting the number of positively staining cells in the three areas of the SM.

In RA, the percentages of IL- $1 \alpha+$, IL- $1 \beta+$, $\mathrm{GM}-\mathrm{CSF}+$ and EGF+ cells were greater in the lining layer compared to the perivascular areas, $(\mathrm{p}<0.002, \mathrm{p}<0.024, \mathrm{p}<0.023$ and $\mathrm{p}<0.039$ respectively) and to the connective tissue areas, $(\mathrm{p}<0.002, \mathrm{p}<0.002, \mathrm{p}<0.002, \mathrm{p}<0.0034$ respectively). Furthermore, GM-CSF staining was more intense in the lining layer compared to the perivascular $(p<0.016)$ and connective tissue areas $(p<0.039)$, TNF- $\alpha$ staining was more intense in the lining layer compared to the connective tissue areas $(p<0 \cdot 048)$, and 

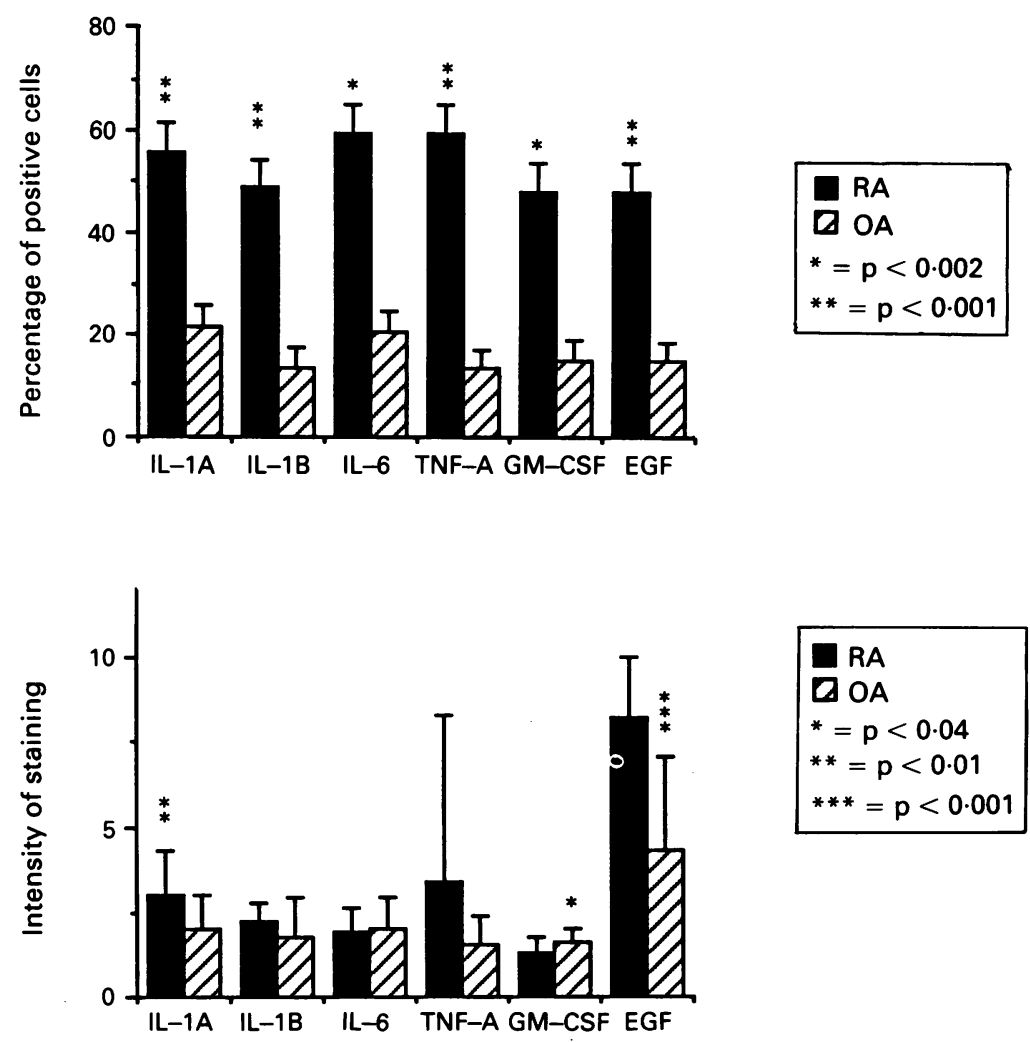

Figure 2 Measurement of the cytokines interleukin-1 alpha (IL-1A), interleukin-1 beta (IL-1B), tumour necrosis factor alpha (TNF-A), interleukin-6 (IL-6), epidermal growth factor (EGF) and granulocyte macrophage-colony stimulating factor (GM-CSF) in the perivascular areas of the synovial membranes of patients with rheumatoid arthritis and osteoarthritis. Upper panel: percentage of positively staining cells; lower panel: intensity of staining.
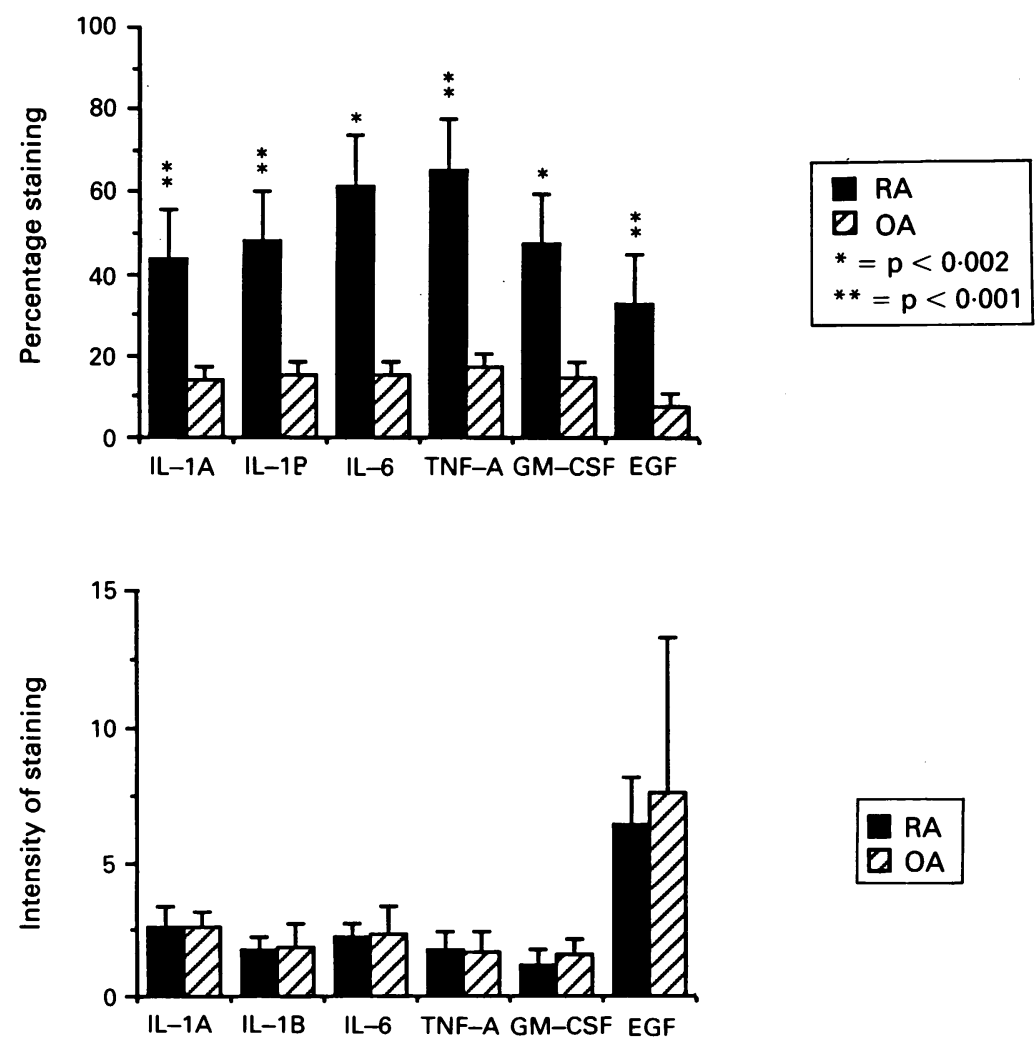

Figure 3 Measurement of the cytokines interleukin-1 alpha (IL-1A), interleukin-1 beta (IL-1B), tumour necrosis factor alpha (TNF-A), interleukin-6 (IL-6), epidermal growth factor (EGF) and granulocyte macrophage-colony stimulating factor (GM-CSF) in the connective tissue areas of the synovial membranes of patients with rheumatoid arthritis and osteoarthritis. Upper panel: percentage of positively staining cells; lower panel: intensity of staining.
EGF staining was more intense in the perivascular areas compared to the connective tissue areas $(p<0.0039)$.

In OA, the percentages of IL-1 $\beta+$, and $\mathrm{EGF}+$ cells were greater in the lining layer than in the perivascular areas, $(p<0.0098$ and $\mathrm{p}<0.002$ respectively) and the percentages of IL- $1 \alpha+$, EGF + and IL- $6+$ cells were greater than in the connective tissue areas, $(p<0.002$, $\mathrm{p}<0.002$ and $\mathrm{p}<0.027$ respectively) Furthermore, the percentages of IL-1 $\alpha+$ and $\mathrm{EGF}+$ cells were greater in the perivascular areas compared to the connective tissue areas, ( $p<0.016$ and $p<0.002$ respectively). The intensities of IL- $1 \alpha$, IL-1 $\beta$ and GM-CSF staining in the lining layer were greater than in the perivascular $(p<0.002, p<0.002$ and $\mathrm{p}<0.027$ respectively) and connective tissue areas $(\mathrm{p}<0.002, \mathrm{p}<0.002$ and $\mathrm{p}<0.005$ respectively). The intensity of staining of EGF in the lining layer was greater than in the perivascular areas $(p<0.014)$.

When cytokine expression was compared in the two patient groups it was found that in the lining layer (fig 1), perivascular (fig 2), and connective tissue areas (fig 3), there were significantly greater numbers of IL- $1 \alpha+$, IL$1 \beta+$, TNF- $\alpha+, \mathrm{IL}-6+, \mathrm{GM}-\mathrm{CSF}+$ and EGF+ cells in RA than in OA SM (fig $4 a, b, c, d$ ).

In the lining layer and perivascular areas, the intensities of staining for IL-1 $\alpha$ and EGF were greater in RA SM, in contrast to GM-CSF staining which was more intense in OA SM in both areas $(p<0.01)$. No statistically significant differences were observed in the intensity of cytokine staining in the connective tissue areas.

\section{Discussion}

We have studied cytokine expression in SMs obtained at knee arthroplasty from 10 patients with $\mathrm{RA}$ and 10 with $\mathrm{OA}$ in an attempt to determine whether different patterns of cellular infiltration and cytokine activity can be related to either diagnosis or disease pattern.

The differences in the composition of the cellular infiltrate were quantitative and most obvious in the perivascular areas. Greater numbers of lymphoid aggregates were noted in RA SM. The presence of these aggregates has been associated with greater production of IL$1 \beta$ and IL-6 in vitro by SM cultures ${ }^{12}$ suggesting that these may be sites of immunological activity. A number of immunohistological studies in cartilage and synovium have demonstrated an inflammatory component in OA. ${ }^{3413-15}$ It has been suggested that a common basic immunohistological pattern is found in RA, OA and traumatic arthritis ${ }^{316}$ and that conclusion pertaining to immunological mechanisms may be invalid. ${ }^{17}$ However, the identification of an MNC and occasional lymphoid aggregates similar to those found in RA may reflect a non-specific reaction to tissue damage rather than inflammation drive by immunological events.

The thicker lining layer and greater degree of vascularity noted in RA SM compared to $O A$ are interesting in the light of the 

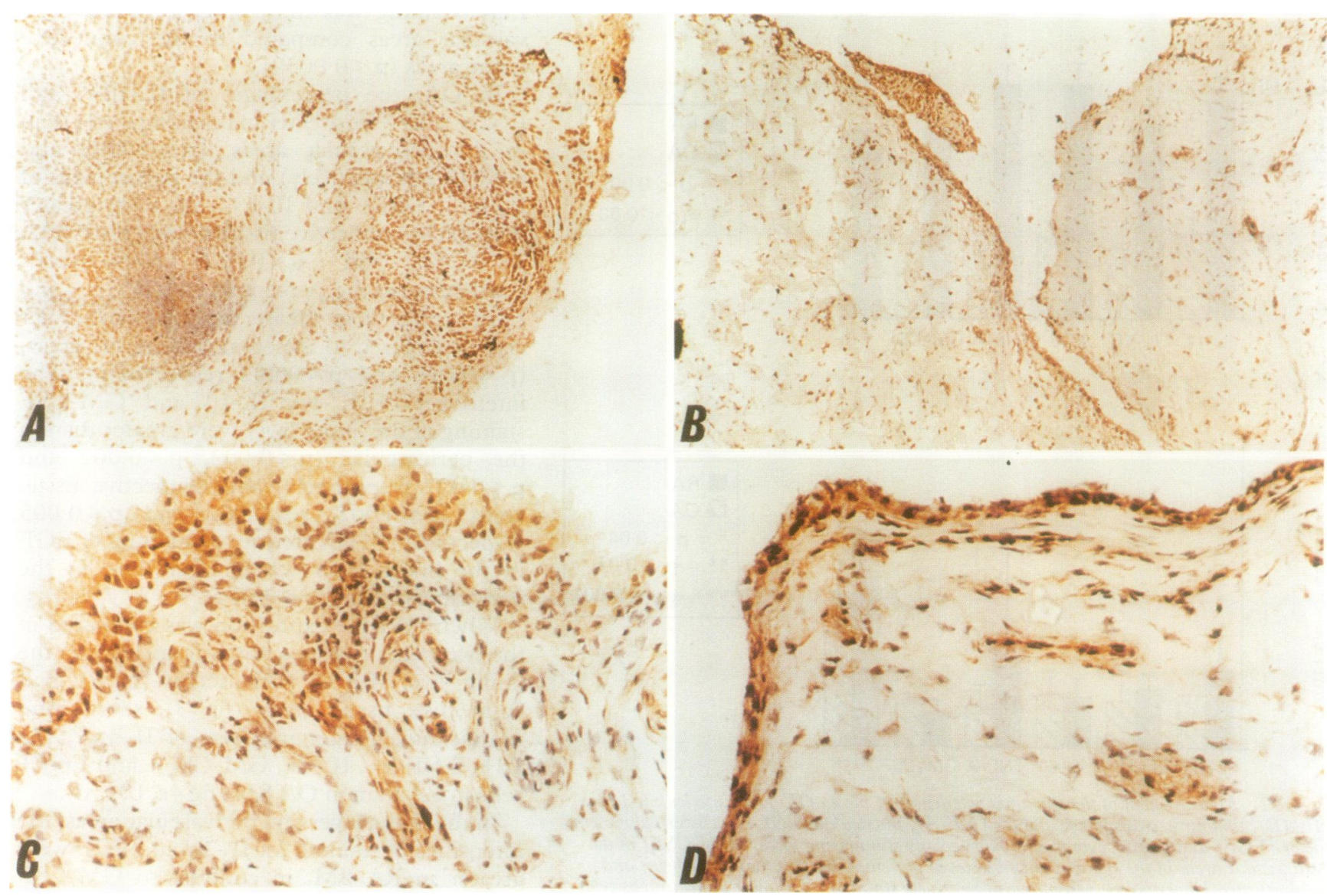

Figure 4 (A) Interleukin-1 $\beta$ staining in the rheumatoid synovial membrane (magnification $\times 312 \cdot 5)$; (B) Interleukin-1 $\beta$ staining in the osteoarthritic synovial membrane (magnification $\times 312 \cdot 5$ ); (C) Tumour necrosis factor- $\alpha$ staining in the rheumatoid synovial membrane (magnification $\times 650)$;

(D) Tumour necrosis factor- $\alpha$ staining in the osteoarthritic synovial membrane (magnification $\times 650)$.

information emerging about the synovial lining cells. The synovial intima contains two cell populations with different origins and functions. Type A cells appear to be bone marrow derived mature monocyte/macrophages which are constantly replaced via the circulation. Type B cells are fibroblast-like cells. An increase in the number of cells which occupy the synovial lining layer is a striking observation in RA. This is noted as early as one month of disease onset ${ }^{18}$ and in clinically uninvolved knee joints of patients with RA. ${ }^{19}$ The increased numbers of cells in the lining layer is due to the increased migration of blood borne monocytes and local proliferation of type $B$ cells. In contrast, psoriatic SM demonstrate significantly less cells in the synovial lining layer when compared to RA and fewer macrophages in the subintimal layers. ${ }^{20}$ Our observations and the ones listed above may suggest that lining layer thickening is a phenomenon unique to RA SM.

Significantly greater percentages of IL-1 $\alpha+$, IL-1 $\beta+$, IL-6+, TNF- $\alpha$, GM-CSF+ and $\mathrm{EGF}+$ cells were detected in all areas of RA SM when compared to OA SM. The one striking difference between OA and RA was that the intensity of GM-CSF staining was greater in the lining layer and perivascular areas of OA SM. In RA, greater numbers of IL$1 \alpha+, \mathrm{IL}-1 \beta+, \mathrm{GM}-\mathrm{CSF}+$ and EGF + cells were counted in the lining layer compared to the perivascular and connective tissue areas, while in OA, these differences were not as obvious. These differences are not surprising as cytokines are essential to the pathogenesis of $\mathrm{RA}$. The detection of these mediators in synovial tissue culture supernatants and synovial fluid have been hampered by limitations inherent to assays of complex biological samples. This study shows that immunohistochemical techniques allow identification and quantification of specific cytokine proteins. The greater amounts of cytokines detected in RA compared to OA are in keeping with the greater degree of inflammation and higher endothelial cell expression of ELAM-1 and VCAM-1 in RA SM. ${ }^{21}$ The preferential localisation of these monokines to the synovial lining layer has been previously observed. ${ }^{22-28}$ The detection of EGF in the synovial lining layer is interesting as it has been previously suggested that it may be responsible for the stratification of the rheumatoid synovial lining layer and perhaps the neovascularisation of RA $S M^{11}$ and may account for the greater lining layer thickness and vascular proliferation observed in RA SM in this study.

The cartilage pannus junction is the site at which RA joint injury takes place. In this area cytokines have been detected in abundant quantities. Macrophages and fibroblasts in erosive pannus produce proteolytic enzymes causing degradation of underlying cartilage. Stromelysin and collagenase $\mathrm{mRNA}$ have been detected at greater levels in the synovial lining 
layer cells of RA SM compared to OA, ${ }^{29-31}$ further supporting the observation that RA is a more aggressive disease. On immunohistochemical staining, specific cytoplasmic stromelysin staining was demonstrated in the RA synovial lining cells, stromal fibroblasts and endothelial cells. ${ }^{32}$ In the same study, rheumatoid synovia demonstrated marked nuclear staining for the proliferation and transformation associated c-myc oncoprotein in contrast to osteoarthritic SM which showed negligible staining. These findings support the belief that the proliferative, invasive behaviour of rheumatoid synoviocytes reflects the expression of biochemical features generally associated with phenotypically transformed malignant tumours.

This study suggests that the differences in cytokine production by $\mathrm{RA}$ and $\mathrm{OA}$ are quantitative rather than qualitative. The greater thickness of the synovial lining layer and higher vascularity may be specific to RA and would result in the higher concentrations of cytokines detected. The similar cytokines profiles in RA and OA suggests that no single cytokine is responsible for a single disease. Future studies should concentrate on biopsy material from patients with early disease and, since the outcome of inflammation within the joint may depend on the balance between cytokines and cytokine inhibitors and receptors, ${ }^{26}{ }^{33}$ the concomitant estimation of cytokine inhibitors.

This study was supported by a core grant (U9) from the Arthritis and Rheumatism Council of Great Britain.

MNF was supported by a Travelling Fellowship from the Egyptian Government.

1 Harris Ed, Jr. Rheumatoid arthritis. Pathophysiology and implication for therapy. $N$ Eng $f$ Med 1990; 332: 1277-89.

2 Firestein G S, Zvaifler N J. How important are T cells in chronic rheumatoid synovitis. Arthritis Rheum 1990; 33. 768-73.

3 Lindblad S, Hedfors E. Arthroscopic and immunohistologic characterisation of knee joint synovitis in osteoarthritis Arthritis Rheum 1987; 30: 1081-88.

4 Revell P A, Mayston V, Lalor P, Mapp P. The synovia membrane in osteoarthritis: a histologic study including the characterisation of the cellular infiltrate present in inflammatory osteoarthritis using monoclonal antibodies. Ann Rheum Dis 1988; 47: 300-7.

5 Walker E R, Boyd R D, Wu D D, Lukoschek M, Burr D B, Radin E L. Morphologic and morphometric changes in synovial membrane associated with mechanically induced osteoarthritis. Arthritis Rheum 1991; 34: 515-24.

6 Arnett F C, Edworthy S M, Bloch D A, et al. The American Rheumatism Association 1987 revised criteria for the classification of rheumatoid arthritis. Arthritis Rheum 1988; 31: 315-24

7 Thorpe R, Wadh W A, Glearing A J H, Mahon B, Poole $\mathrm{S}$. Sensitive and specific immunoradiometric assay for human interleukin alpha. Lymphokine Res 1988; 7 119-24.

8 Boraschi D, Volpini G, Villa L, et al. A monoclonal antibody to the Interleukin-1 beta peptide 163-171 blocks adjuvanticity but not pyrogenicity of IL-1 $\beta$ in vivo. Immunol 1989; 143: 131-4.

9 Hirano T, Matsuda K, Hosoi K, Okano A, Matsui $\mathrm{H}$ Kishimoto T. Absent anti-viral activity in recombinant $\mathrm{B}$ cell stimulatory factor-2 (Bsf-2). Immunol Lett 1988; 17: 41-5.
10 Zenke G, Strittmatter U, Tees R, et al. A cocktail of three monoclonal antibodies significantly increases the sensitivity of an enzyme immunoassay for human granulocyte macrophage colony stimulating factor. $\mathcal{F}$ Immunol 1991; 12: 185-206.

11 Shiozawa S, Shiozawa K, Tanaka Y, et al. Human epidermal growth factor for the stratification of synovial lining layer and neovascularisation in rheumatoid arthritis. Ann Rheum Dis 1989; 48: 820-8.

12 Yanni G, Whelan A W, Feighery C, et al. Contrasting levels of in vitro cytokine production by rheumatoid synovial tissue demonstrating different patterns of mononuclear cell infiltration. Clin Exp Immunol 1993; 93: 387-95.

13 Cooke T D V. Immune pathology in polyarticular Cooke T D V. Immune pathology in
osteoarthritis. Clin Orthop 1986; 213:41-9.

14 Johnell O, Hulth A, Henricson A. T lymphocyte subsets and HLA-DR expressing cells in osteoarthritic synovitis. Scand F Rheumatol 1985; 14: 259-64.

15 Goldberg V M, Kresina T F. Immunology of articular cartilage. $\mathcal{F}$ Rheumatol 1987; 14: 73-6.

16 Lindblad S, Klareskog L, Hedfors E, Forsum U, Sundstrom C. Phenotypic characterisation of synovial tissue cells in situ in different types of synovitis. Arthritis Rheum 1983, 26: 1321-32.

17 Hedfors E. The clinical use of immunohistopathology. $\mathrm{Br}$ f Rheumatol 1989; 28: 278-80.

18 Schumacher H R, Kitridou R C. Synovitis of recent onset. A clinicopathologic study during the first month of disease. Arthritis Rheum 1972; 15: 465-85.

19 Soden M, Rooney M, Cullen A, Whelan A, Feighery C Bresnihan B. Immunohistologic features in the synovium Bresnihan B. Immunohistologic features in the synovium obtained from clinically uninvolved knee joints of patients with rhe $287-92$.

20 Veale D, Yanni G, Rogers S, Barnes L, Bresnihan B, FitzGerald $O$. Reduced synovial macrophage numbers, ELAM-1 expression, and lining layer hyperplasia in psoriatic arthritis as compared with rheumatoid arthritis. Arthritis Rheum 1993; 36: 893-900.

21 Koch A E, Burrows J C, Haines G K, Carlos T M, Harlan J M, Leibovich S J. Immunolocalisation of endothelial and leukocyte adhesion molecules in human rheumatoid and osteoarthritic synovial tissue. Lab Invest 1991; 64 313-20.

22 Firestein G S, Alvaro-Gracia J M, Maki R. Quantitative analysis of cytokine gene expression in rheumatoid analysis of cytokine gene expression

23 Alvaro-Gracia J M, Zvaifler N J, Brown C B, Kaushansky $\mathrm{K}$, Firestein G S. Cytokines in chronic inflammatory arthritis VI. Analysis of synovial cells involved in GM$\mathrm{CSF}$ production and gene expression in rheumatoid CSF production and gene expression in rheumatoid arthritis and its regulatic

24 Wood N C, Symons J A, Dickens E, Duff G W. In situ hybridization of interleukin-6 in rheumatoid arthritis. Clin Exp Immunol 1992; 87: 183-9.

25 Wood N C, Dickens E, Symons J A, Duff G W. In situ hybridization of interleukin-1 in CD14 positive cells in rheumatoid arthritis. Clin Immunol Immunopathol 1992, 62: $295-300$.

26 Deleuran B W, Chu C Q, Field M, et al. Localisation of IL$1 \alpha$, type 1 IL-1 receptor and IL-1 receptor antagonist in the synovial membrane and cartilage/pannus junction in rheumatoid arthritis. Br $\mathcal{f}$ Rheumatol $1992 ; 31$ : 801-9.

27 Chu C O, Field M, Feldmann M, Maini R N. Localisation of $\mathrm{TNF}-\alpha$ in synovial tissue and at the cartilage pannus
of of TNF- $\alpha$ in synovial tissue and at the cartilage pannus
junction in patients with rheumatoid arthritis. Arthritis junction in patients with

28 Field M, Chu C Q, Feldmann M, Maini R N. Interleukin6 localisation in the synovial membrane in rheumatoid arthritis. Rheumatol Int 1991; 11: 45-50.

29 Firestein G S, Paine M M, Littman B H. Gene expression (collagenase, tissue inhibitor of metalloproteinases, complement and HLA-DR) in rheumatoid arthritis and osteoarthritis synovium: quantitative analysis and effect of intra-articular corticosteroids. Arthritis Rheum 1991; 34 1094-1105.

30 Gravellese E M, Darling J M, Ladd A L, Katz J N, Glimcher $\mathrm{L} \mathrm{H}$. In situ hybridisation studies of stromelysin and collagenase mRNA expression in rheumatoid synovium Arthritis Rheum 1991; 34: 1076-84.

31 McCachren S S. Expression of metalloproteinases and metalloprotease inhibitor in human arthritic synovium. Arthritis Rheum 1991; 34: 1085-93.

32 Case J P, Lafyatis R, Remmers E F, Kumkumian G K Wilder $R$ L. Transin/stromelysin expression in rheumatoid synovium. A transformation-associated metalloproteinase secreted by phenotypically invasive synoviocytes. Am f Pathol 1989; 135: 1055-64

33 Deleuran B W, Chu C Q, Field M, Feldmann M, Maini R N. Localisation of TNF receptor in the synovial tissue in patients with rheumatoid arthritis: implication for local actions of TNF- $\alpha$. Arthritis Rheum 1992; 35: 1170-8. 